Published in final edited form as:

J Breath Res. 2011 September ; 5(3): 037107. doi:10.1088/1752-7155/5/3/037107.

\title{
Effect of the influenza $A(\mathrm{H} 1 \mathrm{~N} 1)$ live attenuated intranasal vaccine on nitric oxide $\left(\mathrm{FE}_{\mathrm{NO}}\right)$ and other volatiles in exhaled breath
}

\author{
A Mashir ${ }^{1,6}$, K M Paschke $^{1}$, D van Duin ${ }^{2}$, N K Shrestha ${ }^{2}$, D Laskowski ${ }^{1,3}$, M K Storer $^{4}$, B \\ Yen-Lieberman ${ }^{5}$, S M Gordon², M Aytekin ${ }^{1}$, and R A Dweik ${ }^{1,3}$
}

1Department of Pathobiology/Lerner Research Institute, Cleveland Clinic, 9500 Euclid Ave, Cleveland, $\mathrm{OH} 44195$, USA ${ }^{2}$ Infectious Disease/Medicine Institute, Cleveland Clinic, 9500 Euclid Ave, Cleveland, OH 44195, USA ${ }^{3}$ Department of Pulmonary, Allergy, and Critical Care Medicine/ Respiratory Institute, Cleveland Clinic, 9500 Euclid Ave, Cleveland, OH 44195, USA ${ }^{4}$ Syft Technologies, Ltd, 3 Craft Place, Middleton, Christchurch, New Zealand ${ }^{5}$ Department of Clinical Pathology, Cleveland Clinic, 9500 Euclid Ave, Cleveland, OH 44195, USA

\section{Abstract}

For the 2009 influenza A (H1N1) pandemic, vaccination and infection control were the main modes of prevention. A live attenuated $\mathrm{H} 1 \mathrm{~N} 1$ vaccine mimics natural infection and works by evoking a host immune response, but currently there are no easy methods to measure such a response. To determine if an immune response could be measured in exhaled breath, exhaled nitric oxide $\left(\mathrm{FE}_{\mathrm{NO}}\right)$ and other exhaled breath volatiles using selected ion flow tube mass spectrometry (SIFT-MS) were measured before and daily for seven days after administering the H1N1 2009 monovalent live intranasal vaccine (FluMist ${ }^{\circledR}$, MedImmune LLC) in nine healthy healthcare workers (age $35 \pm 7$ years; five females). On day 3 after H1N1 FluMist ${ }^{\circledR}$ administration there were increases in $\mathrm{FE}_{\mathrm{NO}}$ (MEAN \pm SEM: day $015 \pm 3$ ppb, day $319 \pm 3 \mathrm{ppb} ; p<0.001$ ) and breath isoprene (MEAN \pm SEM: day $059 \pm 15 \mathrm{ppb}$, day $399 \pm 17 \mathrm{ppb} ; p=0.02$ ). MS analysis identified the greatest number of changes in exhaled breath on day 3 with 137 product ion masses that changed from baseline. The exhaled breath changes on day 3 after H1N1 vaccination may reflect the underlying host immune response. However, further work to elucidate the sources of the exhaled breath changes is necessary.

\section{Introduction}

The influenza A H1N1 2009 pandemic affected over 214 countries and resulted in approximately 43-89 million illnesses and 8870-18 449 deaths worldwide (Center for Disease Control, World Health Organization, 6 August 2010). The influenza A 2009 H1N1 virus strain was an assortment of swine, avian and human influenza viruses that closely resembled the H1N1 virus affecting swine in North America [1]. Additionally, the 2009

dweikr@ccf.org

${ }^{6} \mathrm{AM}$ and KMP are co-first authors. 
strain closely resembled another H1N1 influenza A strain that was prevalent between 19471978 [2].

Immunization with live attenuated or inactivated vaccines is the standard protection from influenza infection. However, when compared to inactivated or subunit vaccines live attenuated influenza vaccines (LAIV) are found to be more effective in protecting against influenza infection on a pandemic scale [3, 4]. LAIV are successful through an immediate, innate antiviral response after vaccination. The 2009 trivalent influenza vaccine was less likely to provide protection from the newer H1N1 strain because of the virus' differences from previous strains. The monovalent vaccine was recommended because of the induction of a more specific host immune response.

A biomolecule possibly linked to influenza infection and vaccination is nitric oxide (NO). NO is a highly reactive free radical with oxidizing properties. It is endogenously produced by an enzyme class called nitric oxide synthases (NOS) which converts the substrate $\mathrm{L}_{\mathrm{L}}$ arginine to L-citrulline with the release of NO. There are three isoforms of NOS: type I NOS (neuronal NOS (nNOS)), type II NOS (inducible NOS (iNOS)) and type III NOS (endothelial NOS (eNOS)). During an inflammatory response, iNOS is either induced by cytokines, endotoxins, or oxidants resulting in an increased NOS expression and NO synthesis [5-8]. NO is measured in exhaled breath by using the fractional exhaled nitric oxide $\left(\mathrm{FE}_{\mathrm{NO}}\right)$. Past studies have identified changes in exhaled $\mathrm{NO}$ after influenza infection, vaccination and upper respiratory tract infections [9-13]. In particular, NO has been shown to peak after viral infection and has been speculated to play a beneficial role in viral clearance [12]. Additionally, $\mathrm{FE}_{\mathrm{NO}}$ measurement is used in the assessment of airway inflammation, particularly in asthmatics. Deviations from the normal range of $\mathrm{FE}_{\mathrm{NO}}$ have also been noted in a number of conditions such as bronchiectasis, cystic fibrosis, liver cirrhosis, pulmonary hypertension, smoking and chronic obstructive pulmonary disease [14].

Beyond $\mathrm{FE}_{\mathrm{NO}}$, breath analysis is rapidly evolving as a new frontier in medical testing for disease states of the lung and beyond. Considerable advances have been made in the field of exhaled breath analysis during the 21 st century and the utility of breath analysis in healthcare is developing quickly. Exhaled breath analysis is currently used to diagnose and monitor asthma, check for transplant organ rejection, and to detect lung cancer, alcohol intoxication and Helicobacter pylori infection, among a few of its clinical applications.

We hypothesize that the immune response to live virus vaccination can result in detectable changes in $\mathrm{FE}_{\mathrm{NO}}$ and other volatile organic compounds (VOCs) in exhaled breath. Currently, there is no non-invasive method to measure the host immune response to the H1N1 influenza vaccine or active infection.

\section{Methods}

\subsection{Study population}

Healthy Cleveland Clinic workers scheduled to receive the 2009 H1N1 monovalent live intranasal vaccine (FluMist ${ }^{\circledR}$, Medimmune LLC) were recruited to participate in the study. A total of 11 individuals (MEAN \pm SD: age $35 \pm 7$ years; females $=5$ ) were enrolled. One 
exhaled breath sample and $\mathrm{FE}_{\mathrm{NO}}$ measurement were obtained prior to receiving the vaccine (day 0 ) and daily after vaccination for seven days (days 1-7). All subjects were non-smokers and signed an Institutional Review Board approved consent form prior to participation in the study. Subjects were tested for influenza A (nasopharyngeal swab for influenza A, B and respiratory syncytial virus (RSV) by polymerase chain reaction) on day 0 (prior to vaccination) and day 1 . Subjects who tested positive for influenza or RSV prior to vaccination $(n=2)$ were released from the study.

\subsection{H1N1 influenza vaccine}

All subjects received the $2009 \mathrm{H} 1 \mathrm{~N} 1$ monovalent live attenuated intranasal vaccine. The vaccine was administered at a dose of $0.2 \mathrm{ml}(0.1 \mathrm{ml}$ each nare) on day 0 of the study.

\section{3. $F E_{\mathrm{NO}}$ measurement}

One $\mathrm{FE}_{\mathrm{NO}}$ sample was provided by each study participant prior to vaccination $(n=6)$ on day 0 and after vaccination on days $1-7(n=9)$. The $\mathrm{FE}_{\mathrm{NO}}$ measurement was completed prior to exhaled breath sample collection. $\mathrm{FE}_{\mathrm{NO}}$ was measured using a $\mathrm{NIOX} \mathrm{MINO}^{\circledR}$ (Aerocrine AB, Solna, Sweden).

\subsection{Exhaled breath sample collection}

One exhaled breath sample was provided by each study participant $(n=9)$ prior to vaccination on day 0 and again on days $1-7$. Subjects were asked to produce one exhaled breath sample through an exhaled breath collection device (figure 1). They were asked to exhale normally to release residual air from the lungs. The subject was prompted to inhale to the capacity of the lungs through a disposable mouth filter (Aerocrine, AB, Solna, Sweden) and an attached N7500-2 Acid Gas Cartridge (North Safety LLC, USA). The subject exhaled at an approximate rate of $350 \mathrm{ml} \mathrm{s}^{-1}$ through the device. The exhaled breath sample was collected in the attached Mylar ${ }^{\circledR}$ bag, capped and analyzed within $4 \mathrm{~h}$. Mylar ${ }^{\circledR}$ bags were cleaned by flushing with 51 of nitrogen between subjects.

\subsection{Analysis of exhaled breath using SIFT-MS}

Exhaled breath samples were analyzed using selected ion flow tube mass spectrometry (SIFT-MS) [15]. The instrument used in this study was a VOICE200 ${ }^{\circledR}$ SIFT-MS instrument (Syft Technologies Ltd, Christchurch, New Zealand, www.syft.com) (figure 1) that has been described elsewhere [16].

Mass-selected $\mathrm{H}_{3} \mathrm{O}^{+}, \mathrm{NO}^{+}$and $\mathrm{O}_{2}^{+}$ions generated from a microwave air discharge at $\sim 0.5$ Torr are admitted into a flow tube reactor where they are carried along the flow tube in a stream of helium. Breath samples containing the analytes for analysis are admitted into the flow tube at a known rate through a heated variable leak valve at the sample inlet. All the ion products of the chemical ionization reaction and un-reacted reagent ions are monitored by a quadrupole mass filter and an ion counting system at the downstream end of the flow tube reactor.

Data were obtained under two modes of operation. In the mass scanning (MS) mode, mass scans were obtained of the ions generated in the chemical ionization mass spectrum (15-200 
amu) for each reagent ion with switching between reagent ions being automatic on a millisecond time scale. A total of 558 product ion masses were scanned for during the MS analysis. Data were also obtained in the selected ion monitoring mode (SIM) where product ions for selected compounds of interest (table 1) were monitored for longer times than occurred in the MS mode providing more accurate concentration data. The subset of product ions selected was chosen to avoid interference from other known breath analytes. The 11 compounds, 2-propanol, acetone, benzene, ethanol, pentane, methanol, isoprene, toluene, dimethyl sulfide, carbon disulfide and isobutane, were chosen based on previous work our group and others have done in identifying these compounds in the exhaled breath of patients with lung diseases [17].

\subsection{SIFT-MS normalization}

The MS data were normalized to account for variability in the precursor ion intensity by dividing each mass signal by the sum of the corresponding reagent ion signals. The inbuilt LabSYFT software and accompanying libraries (Syft Technologies Ltd) calculated absolute concentrations of SIM analytes from the precursor ion to product ion count ratio, so normalization was not required.

\subsection{Data analysis}

The paired $t$-test was used to analyze changes in breath $\mathrm{FE}_{\mathrm{NO}}$ and to identify significant changes in VOCs and other product ion masses. The Pearson's correlation test was used to identify correlations between the relative change in $\mathrm{FE}_{\mathrm{NO}}$ and other VOCs and product ion masses.

Additionally, MS data were analyzed using linear discriminant analysis. All product ion masses were entered into the discriminant analysis and the ten best masses that discriminate between day 0 and day 3 were chosen during a stepwise variable selection.

\section{Results}

\section{1. $F E_{\mathrm{NO}}$ results}

$\mathrm{FE}_{\mathrm{NO}}$ levels were normal at baseline and peaked on day 3 (MEAN \pm SEM: day $014.7 \pm 2.7$ ppb, day $319.2 \pm 2.8$ ppb; $p<0.001)$. There was no difference in $\mathrm{FE}_{\mathrm{NO}}$ on any other study days compared to baseline (figure 2 ).

\subsection{SIFT-MS results (SIM and MS data)}

Analysis of the SIM data revealed that of the 11 compounds specifically monitored, only breath isoprene changed significantly during the study. Breath isoprene levels were elevated on day 3 compared to baseline (MEAN \pm SEM: day $398.8 \pm 16.8$ ppb, day $059.2 \pm 14.9$ ppb; $p=0.02)$.

The MS data (15-200 amu for each reagent ion) provided evidence that there were many masses where the intensities changed during the study. These masses are the product ions of dozens of compounds which were not specifically identified prior to analysis. The biggest difference in exhaled breath was on day 3 after H1N1 vaccination (figure 3 ). When the 
intensities of the product ion masses on each sample day were compared to baseline there were 38 product ion masses that differed on day 1, 94 product ion masses that differed on day 2,137 product ion masses that differed on day 3, 78 product ion masses that differed on day 4, 25 product ion masses that differed on day 6 and 80 product ion masses that differed on day 7. Interestingly, nearly all of the 137 significant product ion masses on day 3 were decreased compared to baseline.

\subsection{Pearson's correlation test}

The relative change in $\mathrm{FE}_{\mathrm{NO}}$ was negatively correlated to the relative change (baseline and day 3 ) in intensities of 37 of the product ion masses (table 2).

\subsection{Linear discriminant analysis}

Ten discriminant masses were chosen during a stepwise variable selection as part of the discriminant analysis. We scanned between 15-200 amu for each reagent ion $\left(\mathrm{H}_{3} \mathrm{O}^{+}, \mathrm{NO}^{+}\right.$, $\mathrm{O}_{2}^{+}$) in the MS analysis resulting in 558 product ion masses scanned for. All 558 product ion masses were entered into the discriminant analysis and the 10 best masses that discriminate between day 0 and day 3 were chosen. These 10 masses are derived from any of the three reagent ions and they identify with at least a couple different VOCs. However, we are unsure of which specific VOCs they represent. The three most significant masses $\left(\mathrm{H}_{3} \mathrm{O}^{+} 143^{+}, \mathrm{NO}^{+} 108^{+}, \mathrm{O}_{2}^{+} 89^{+}\right)$are displayed in figure 4 .

\section{Discussion}

The main finding from our study is that $\mathrm{FE}_{\mathrm{NO}}$ levels peaked at day 3 after live attenuated H1N1 vaccination, which was associated with major changes in the breath profile of other VOCs in the breath. These findings provide preliminary evidence that the immune response to vaccination (and possibly a natural infection) can be detected by analyzing the exhaled breath for $\mathrm{FE}_{\mathrm{NO}}$ and possibly other volatile compounds.

Using $\mathrm{FE}_{\mathrm{NO}}$ to determine which timeframe to target for further analysis of other VOCs in breath is a novel concept that we introduced in this study. While analyzing all breath scans from the seven study days could be a daunting task and may have little yield, we expected that focusing on the study day with the largest change in $\mathrm{FE}_{\mathrm{NO}}$ would be the most effective way to find corresponding changes in a large number of breath VOCs. Our working hypothesis was that if the increase in $\mathrm{FE}_{\mathrm{NO}}$ on day 3 is the reflection of the induced immune response, then we expect to identify other related breath compounds in the MS data on the same day. Our approach was validated when we found that of all the days studied day 3 had the largest magnitude of change from baseline in both $\mathrm{FE}_{\mathrm{NO}}$ and exhaled breath compounds (figure 3). Additionally, previous findings suggest that day 3 after H1N1 influenza and human rhinovirus infection has the highest number and severity of symptoms related to infection validating why a host immune response would be prominent on day 3 after viral exposure $[10,12]$. Interestingly, many previous studies identified a slight increase in $\mathrm{FE}_{\mathrm{NO}} 1$ week after infection or vaccine, whereas we identified the increase on day 3 after vaccination. This may be due to a faster host immune response to the monovalent live vaccine as opposed to actual infection or use of the trivalent vaccine. Additionally, in 
previous studies the $\mathrm{FE}_{\mathrm{NO}}$ and symptom score (number and severity of symptoms) are negatively correlated, suggesting that a $\mathrm{FE}_{\mathrm{NO}}$ increase helps with viral clearance and protection from exacerbations of asthma [12, 18].

On day 3 we identified an increase in isoprene, a major constituent of exhaled breath produced endogenously. As reported in several studies, increased levels of breath isoprene can reflect airway oxidative stress, offering a possible explanation for the increase in isoprene on day 3 along with $\mathrm{FE}_{\mathrm{NO}}$ [19]. However, isoprene is mainly produced endogenously but can be influenced by variables such as exercise, sleep, age, cholesterol biosynthesis, medications and certain diseases [20-26]. Our sampling protocol accounted for many of these variables by enrolling healthy subjects who were sampled in the morning at work and not during exercise. Thus, it may be plausible to assume that the increase in breath isoprene on day 3 was also associated with the host response to the vaccine.

Interestingly, the relative change of $\mathrm{FE}_{\mathrm{NO}}$ was negatively correlated to the relative change of the 37 product ion masses we identified in the MS analysis between baseline and day 3 . Thus, as $\mathrm{FE}_{\mathrm{NO}}$ increased many breath VOCs decreased in a related way. While this is not what we expected, it is certainly possible that airway inflammation may cause a decrease in the rate of diffusion of VOCs into the lungs explaining why we found a reduction in exhaled breath compounds on day 3 .

Our group and others have studied the signature of the Mylar bags. We recognize that Mylar, much like any other collection reservoir, contributes VOCs to the sample. Our rationale for using this material was that all subjects had an off-line breath collected into Mylar bags and the same Mylar bags were used throughout the study. Since we looked at the change in exhaled breath volatiles we would not expect a Mylar bag VOC contribution to change overtime (duration of this study) and we believe it was not a contributing effect.

The mechanism(s) underlying this change in $\mathrm{FE}_{\mathrm{NO}}$ and other breath volatiles in response to the live vaccine remain to be elucidated and require further study. Further work is also needed to identify the specific compounds in the MS data and link those compounds to the corresponding metabolic and inflammatory pathways. While the compounds identified in the SIM and MS data may be explained by metabolic end products that differ because of the underlying disease process or immune response, it is also possible that some differences can be attributed to exogenous sources such as exposure to VOCs, ingestion of certain foods, or gut bacterial flora. In either case, our findings have several important practical implications given the fact that there are currently no easy non-invasive methods to measure the immune response to a vaccine or actual infection.

\section{Acknowledgment}

This work was supported in part by a Third Frontier grant from the Ohio Department of Development.

\section{References}

[1]. Kistner O, et al. A whole virus pandemic influenza H1N1 vaccine is highly immunogenic and protective in active immunization and passive protection mouse models. PLoS ONE. 2010; 5:e9349. [PubMed: 20186321] 
[2]. Nicholson KG, et al. Clinical studies of monovalent inactivated whole virus and subunit A/ USSR/77 (H1N1) vaccine: serological responses and clinical reactions. J. Biol. Stand. 1979; 7:123-36. [PubMed: 479199]

[3]. Mallory RM, Malkin E, Ambrose CS, Bellamy T, Shi L, Yi T, Jones T, Kemble G, Dubovsky F. Safety and immunogenicity following administration of a live, attenuated monovalent 2009 H1N1 influenza vaccine to children and adults in two randomized controlled trials. PLoS ONE. 2010; 5:e13755. [PubMed: 21060780]

[4]. Yang P, et al. Immunogenicity and protective efficacy of a live attenuated vaccine against the 2009 pandemic A H1N1 in mice and ferrets. Vaccine. 2011; 29:698-705. [PubMed: 21111782]

[5]. Mulligan MS, Hevel JM, Marletta MA, Ward PA. Tissue injury caused by deposition of immune complexes is 1-arginine dependent. Proc. Natl Acad. Sci. USA. 1991; 88:6338-42. [PubMed: 1648737]

[6]. Hutcheson IR, Whittle BJ, Boughton-Smith NK. Role of nitric oxide in maintaining vascular integrity in endotoxin-induced acute intestinal damage in the rat. Br. J. Pharmacol. 1990; 101:815-20. [PubMed: 2085706]

[7]. Petros A, Bennett D, Vallance P. Effect of nitric oxide synthase inhibitors on hypotension in patients with septic shock. Lancet. 1991; 338:1557-8. [PubMed: 1720856]

[8]. Fang FC. Perspectives series: host/pathogen interactions. Mechanisms of nitric oxide-related antimicrobial activity. J. Clin. Invest. 1997; 99:2818-25. [PubMed: 9185502]

[9]. Thomas PS, Ng C, Elsing M, Yates DH. Influenza vaccination: changes in exhaled nitric oxide levels and sputum cytology. Respirology. 1999; 4:355-8. [PubMed: 10612568]

[10]. Murphy AW, Platts-Mills TA, Lobo M, Hayden F. Respiratory nitric oxide levels in experimental human influenza. Chest. 1998; 114:452-6. [PubMed: 9726729]

[11]. de Gouw HW, Hendriks J, Woltman AM, Twiss IM, Sterk PJ. Exhaled nitric oxide (NO) is reduced shortly after bronchoconstriction to direct and indirect stimuli in asthma. Am. J. Respir. Crit. Care Med. 1998; 158:315-9. [PubMed: 9655746]

[12]. Sanders SP, Proud D, Permutt S, Siekierski ES, Yachechko R, Liu MC. Role of nasal nitric oxide in the resolution of experimental rhinovirus infection. J. Allergy Clin. Immunol. 2004; 113:697702. [PubMed: 15100676]

[13]. Kharitonov SA, Yates D, Barnes PJ. Increased nitric oxide in exhaled air of normal human subjects with upper respiratory tract infections. Eur. Respir. J. 1995; 8:295-7. [PubMed: 7538934]

[14]. ATS; ERS. ATS/ERS recommendations for standardized procedures for the online and offline measurement of exhaled lower respiratory nitric oxide and nasal nitric oxide. Am. J. Respir. Crit. Care Med. 2005; 171:912-30. [PubMed: 15817806]

[15]. Smith D, Spanel P. Selected ion flow tube mass spectrometry (SIFT-MS) for on-line trace gas analysis. Mass Spectrom. Rev. 2005; 24:661-700. [PubMed: 15495143]

[16]. Prince BJ, Milligan DB, McEwan MJ. Application of selected ion flow tube mass spectrometry to real-time atmospheric monitoring. Rapid Commun. Mass Spectrom. 2010; 24:1763-9. [PubMed: 20499321]

[17]. Machado RF, et al. Detection of lung cancer by sensor array analyses of exhaled breath. Am. J. Respir. Crit. Care Med. 2005; 171:1286-91. [PubMed: 15750044]

[18]. de Gouw HW, Grunberg K, Schot R, Kroes AC, Dick EC, Sterk PJ. Relationship between exhaled nitric oxide and airway hyperresponsiveness following experimental rhinovirus infection in asthmatic subjects. Eur. Respir. J. 1998; 11:126-32. [PubMed: 9543281]

[19]. Risby TH, Sehnert SS. Clinical application of breath biomarkers of oxidative stress status. Free Radic. Biol. Med. 1999; 27:1182-92. [PubMed: 10641709]

[20]. Deneris ES, Stein RA, Mead JF. In vitro biosynthesis of isoprene from mevalonate utilizing a rat liver cytosolic fraction. Biochem. Biophys. Res. Commun. 1984; 123:691-6. [PubMed: 6487307]

[21]. Karl T, Prazeller P, Mayr D, Jordan A, Rieder J, Fall R, Lindinger W. Human breath isoprene and its relation to blood cholesterol levels: new measurements and modeling. J. Appl. Physiol. 2001; 91:762-70. [PubMed: 11457792]

[22]. Amann, A.; Smith, D. Breath Analysis for Clinical Diagnosis and Therapeutic Monitoring. World Scientific; Singapore: 2005. 
[23]. Taucher J, Hansel A, Jordan A, Fall R, Futrell JH, Lindinger W. Detection of isoprene in expired air from human subjects using proton-transfer-reaction mass spectrometry. Rapid Commun. Mass Spectrom. 1997; 11:1230-4. [PubMed: 9260307]

[24]. Smith D, Spanel P, Enderby B, Lenney W, Turner C, Davies SJ. Isoprene levels in the exhaled breath of 200 healthy pupils within the age range $7-18$ years studied using SIFT-MS. J. Breath Res. 2010; 4:017101. [PubMed: 21386206]

[25]. Lirk P, Bodrogi F, Raifer H, Greiner K, Ulmer H, Rieder J. Elective haemodialysis increases exhaled isoprene. Nephrol. Dial. Transplant. 2003; 18:937-41. [PubMed: 12686668]

[26]. McGrath LT, Patrick R, Silke B. Breath isoprene in patients with heart failure. Eur. J. Heart Fail. 2001; 3:423-7. [PubMed: 11511427]

[27]. Spanel P, Smith D. SIFT studies of the reactions of $\mathrm{H}_{3} \mathrm{O}^{+}, \mathrm{NO}^{+}$and $\mathrm{O}_{2}{ }^{+}$with a series of alcohols. Int. J. Mass Spectrom. Ion Process. 1997; 167-168:375-88.

[28]. Spanel P, Ji Y, Smith D. SIFT studies of the reactions of $\mathrm{H}_{3} \mathrm{O}^{+}, \mathrm{NO}^{+}$and $\mathrm{O}_{2}{ }^{+}$with a series of aldehydes and ketones. Int. J. Mass Spectrom. Ion Process. 1997; 165-166:25-37.

[29]. Spanel P, Smith D. Selected ion flow tube studies of the reactions of $\mathrm{H}_{3} \mathrm{O}^{+}, \mathrm{NO}^{+}$and $\mathrm{O}_{2}{ }^{+}$with several aromatic and aliphatic hydrocarbons. Int. J. Mass Spectrom. 1998; 181:1-10.

[30]. Spanel P, Smith D. Selected ion flow tube studies of the reactions of $\mathrm{H}_{3} \mathrm{O}^{+}, \mathrm{NO}^{+}$, and $\mathrm{O}_{2}{ }^{+}$with some organosulphur molecules. Int. J. Mass Spectrom. 1998; 176:167-76. 


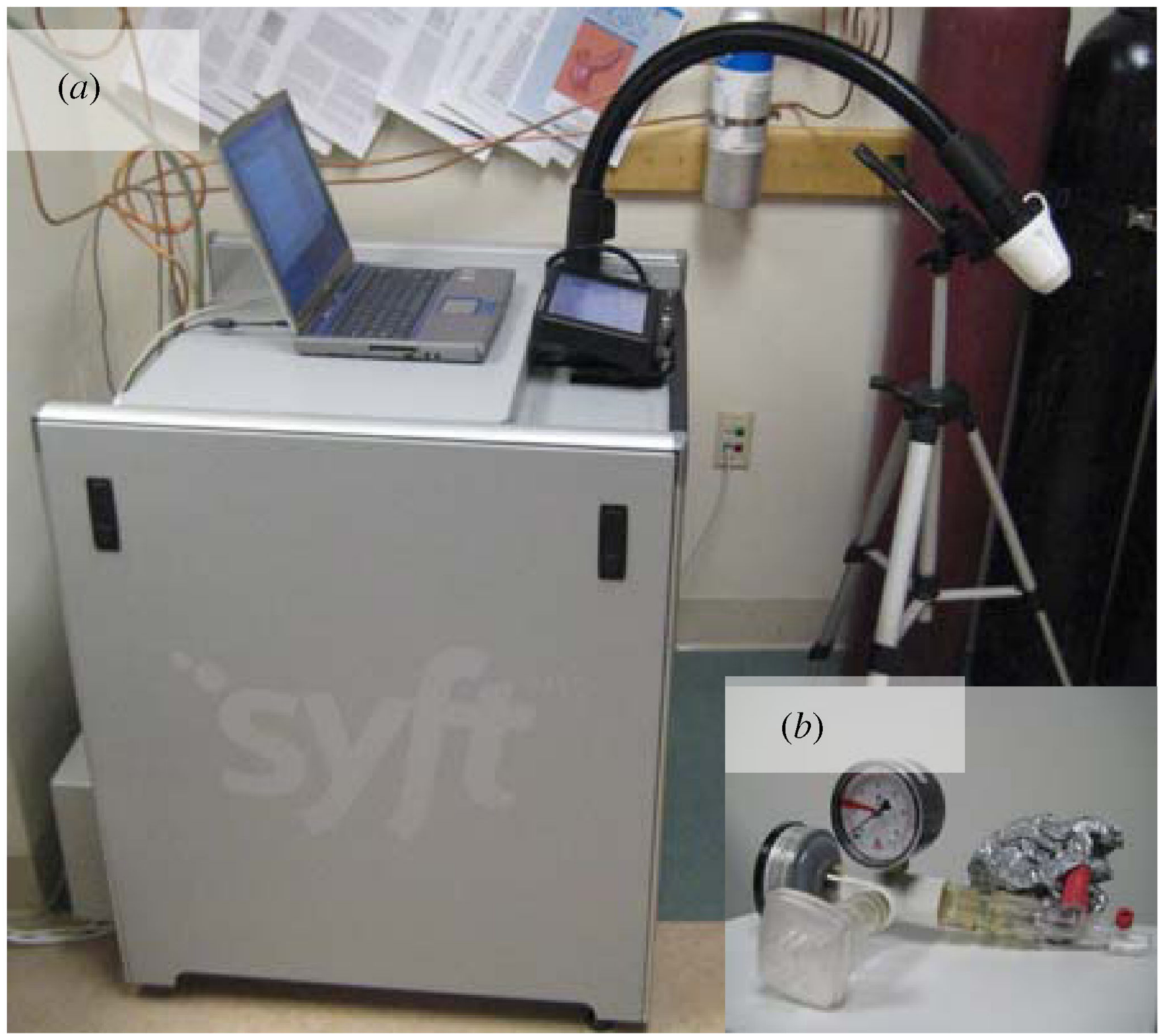

Figure 1.

(a) SIFT-MS instrument. (b) Exhaled breath collection device consisting of an air filter, flow meter, mouth filter and breath collection bag. Reproduced with permission from Syft Technologies. 


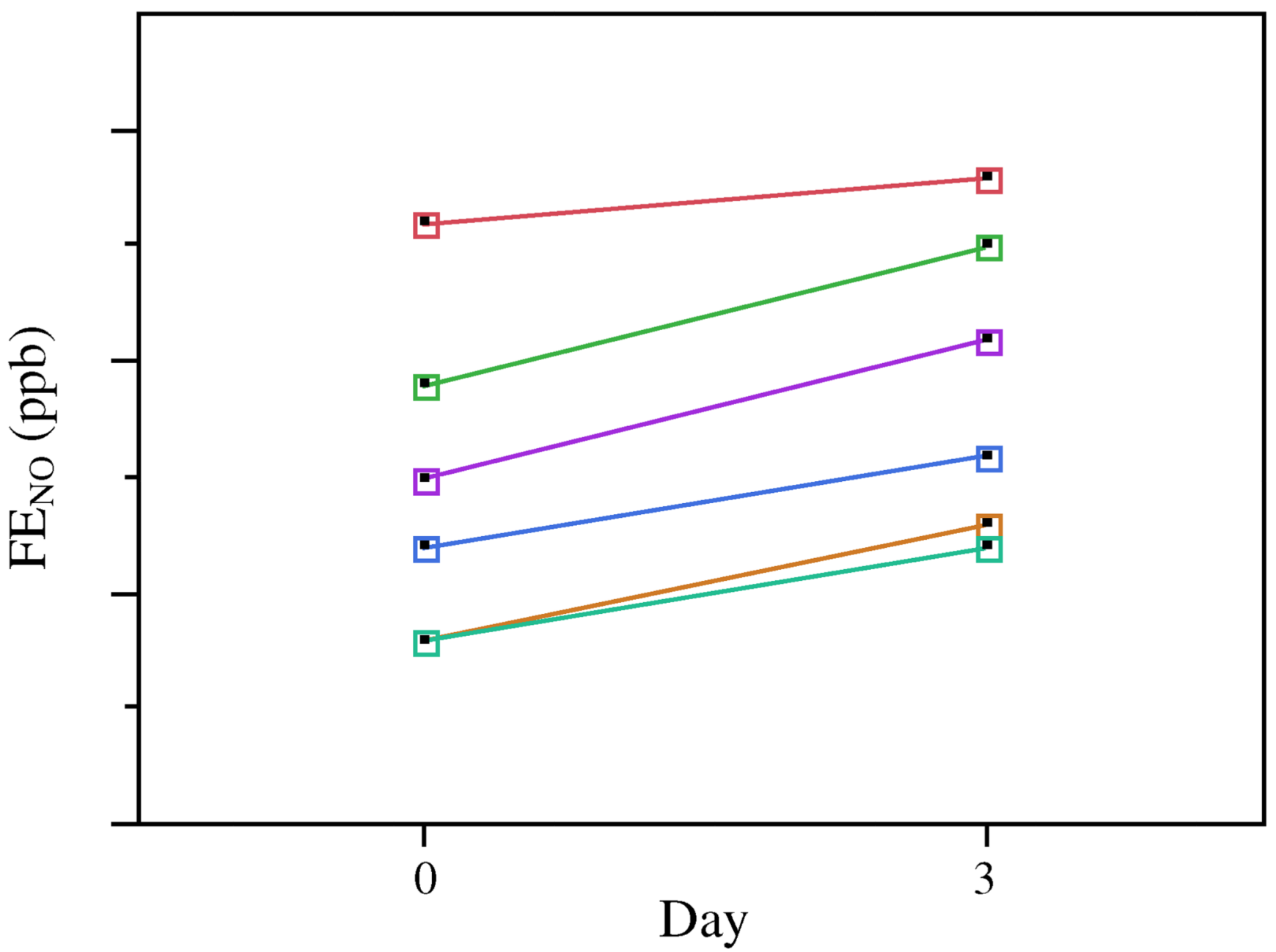

Figure 2.

$\mathrm{FE}_{\mathrm{NO}}(n=6)$ was higher on day 3 compared to baseline (day 0 ). 


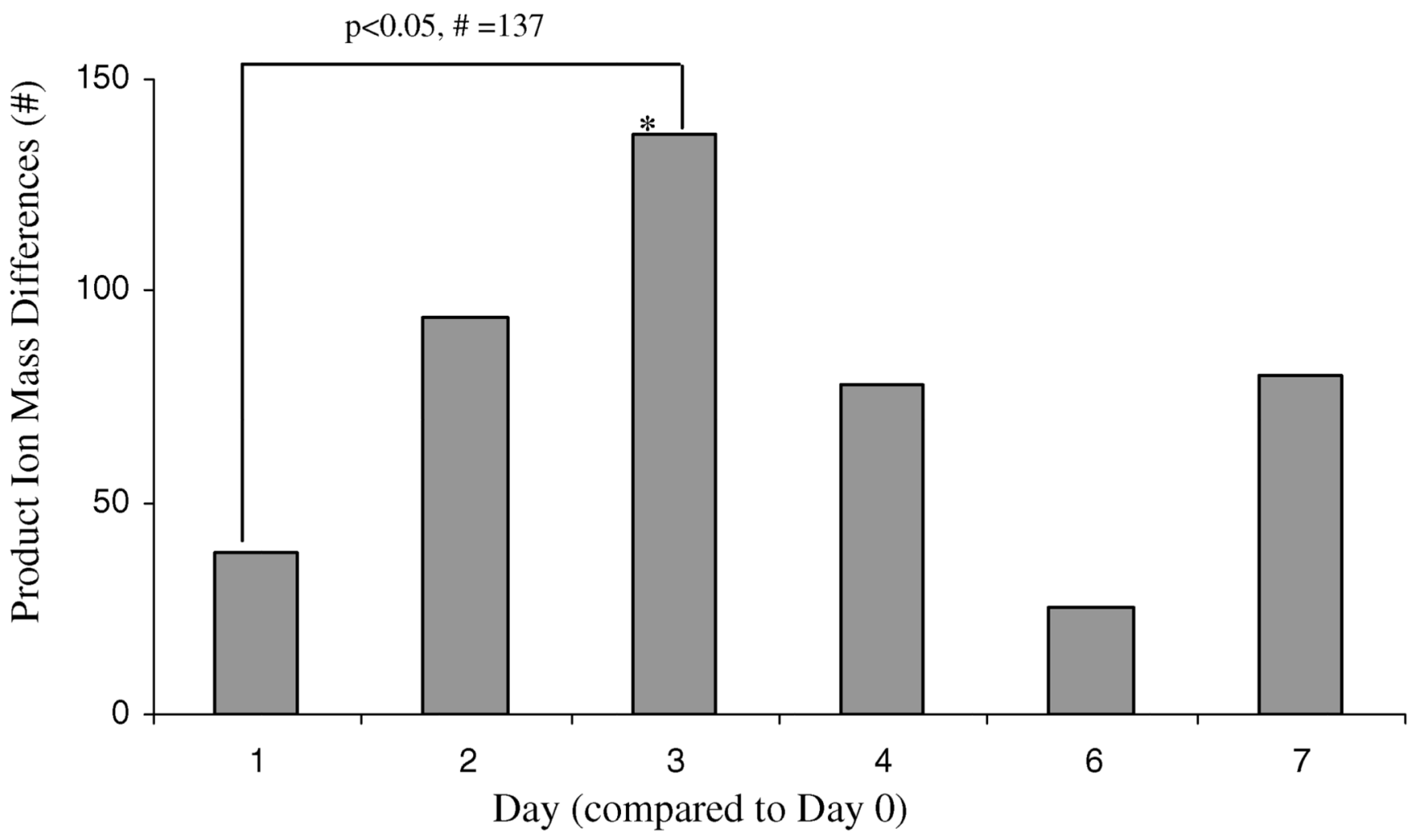

Figure 3.

The number of differences in product ion masses from the MS data representing exhaled breath volatiles on days 1-7 after vaccination. The greatest number of product ion masses that changed after baseline (day 0 ) occurred on day 3 . 


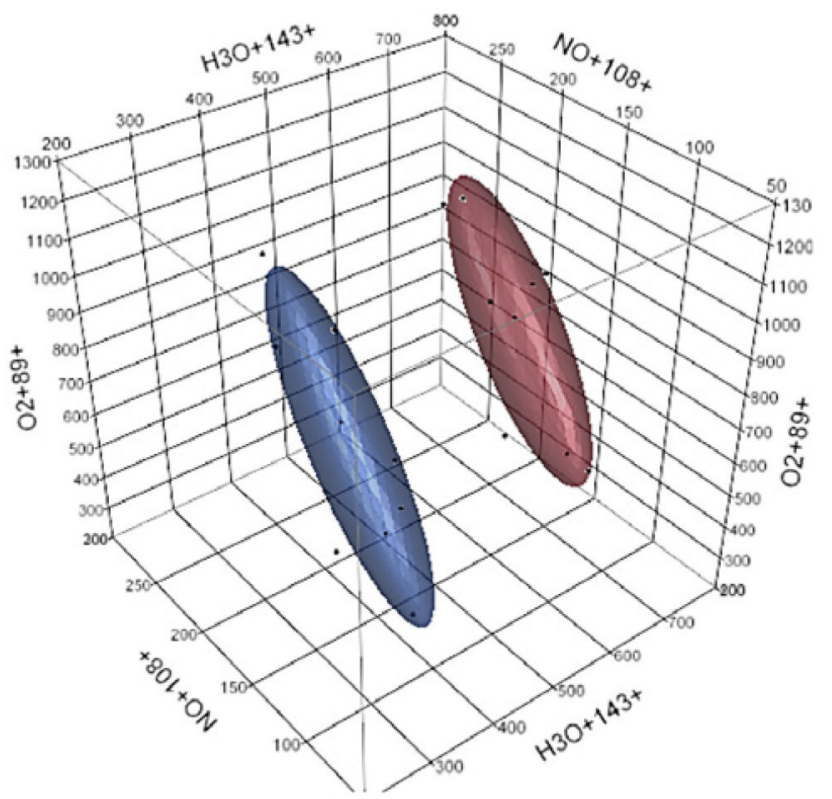

(a)

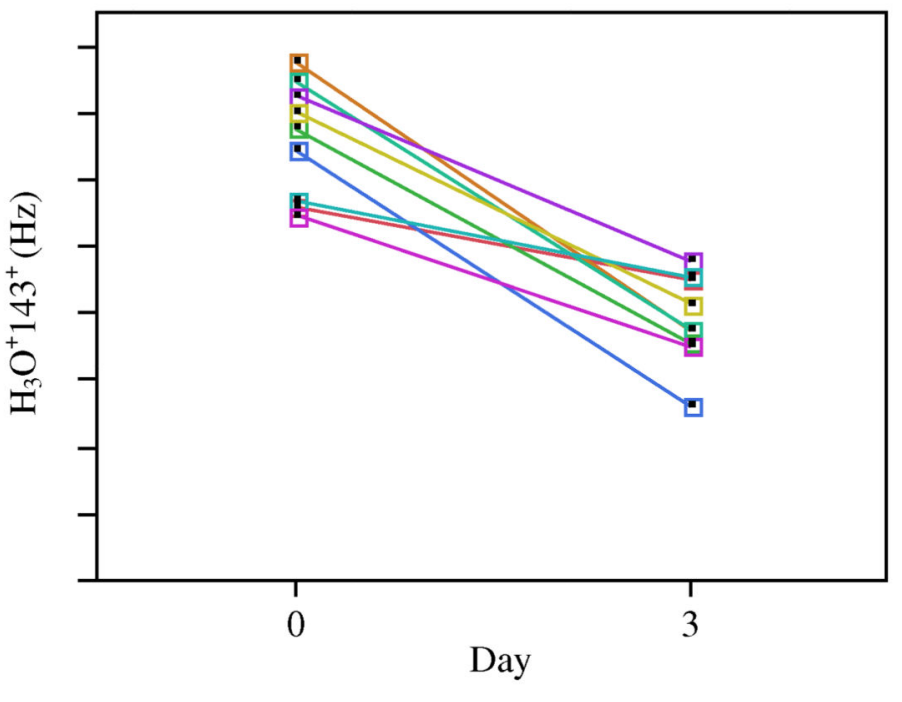

(b)

Figure 4.

(a) The top three product ion masses identified by discriminant analysis capable of classifying subjects into day 0 or day 3 groups. Normal contour ellipsoids are displayed in red (day 0 ) on the left, and blue (day 3 ) on the right. (b) Comparison of one selected product ion mass between day 0 and day 3 . 
Table 1

Exhaled breath compounds, their sources and precursor ion masses used in the SIM analysis.

\begin{tabular}{llll}
\hline Analyte & Possible source & Precursor ion & Mass \\
\hline 2-propanol & Reduction of acetone, exogenous & $\mathrm{H}_{3} \mathrm{O}^{+}$ & $43[27]$ \\
Acetone & Ketone bodies, stress, dieting, fasting & $\mathrm{NO}^{+}$ & $88[28]$ \\
Benzene & Exogenous & $\mathrm{O}_{2}{ }^{+}$ & $78[29]$ \\
Carbon disulfide & Gut bacteria, exogenous & $\mathrm{O}_{2}{ }^{+}$ & $76[30]$ \\
Dimethyl sulfide & Oral malodor, incomplete breakdown of methionine, gut bacteria & $\mathrm{O}_{2}{ }^{+}$ & $62[30]$ \\
Ethanol & Gut bacteria, exogenous & $\mathrm{NO}^{+}$ & $45[27]$ \\
Isobutane & Cholesterol biosynthesis, ageing & $\mathrm{O}_{2}{ }^{+}$ & $56[29]$ \\
Isoprene & Exogenous & $\mathrm{O}_{2}{ }^{+}$ & $53[29]$ \\
Methanol & Gut bacteria, hydrolysis of leaving methyl groups & $\mathrm{H}_{3} \mathrm{O}^{+}$ & $33[27]$ \\
Pentane & Lipid peroxidation & $\mathrm{O}_{2}{ }^{+}$ & $72[29]$ \\
Toluene & Exogenous & $\mathrm{O}_{2}{ }^{+}$ & $92[29]$ \\
\hline
\end{tabular}




\section{Table 2}

Correlations between the relative change in product ion masses from the MS data and the relative change in $\mathrm{FE}_{\mathrm{NO}}$. Relative change is a comparison of the change between day 3 and baseline (day 0 ). The relative change in the intensity of 37 product ion masses was correlated to the relative change of $\mathrm{FE}_{\mathrm{NO}}$.

\begin{tabular}{lll}
\hline $\begin{array}{l}\text { Number of } \\
\text { correlations }\end{array}$ & $\begin{array}{l}\text { Pearson's } \\
\text { correlation }(\boldsymbol{r})\end{array}$ & Significance $(\boldsymbol{p})$ \\
\hline 14 & -0.95 & $p<0.01$ \\
23 & -0.86 & $p=0.01-0.05$ \\
\hline
\end{tabular}

